This document is the Accepted Manuscript version of a Published Work that appeared in final form in Macromolecules 52(16) : 6274-6284 (2019), copyright (C) 2019 American Chemical Society after peer review and technical editing by the publisher. To access the final edited and published work see https://doi.org/10.1021/ acs.macromol.9b01078

\title{
Nucleation of poly(lactide) on the surface of different fibers
}

\author{
Bao Wang ${ }^{\mathrm{a}}$, Tao Wen ${ }^{\mathrm{b}}$, Xiuqin Zhang ${ }^{\mathrm{c}}$, Agnieszka Tercjak ${ }^{\mathrm{d}}$, Xia Dong ${ }^{\mathrm{b}}$, Alejandro J. \\ Müller ${ }^{\mathrm{e}, \mathrm{f}}$, Dujin Wang ${ }^{\mathrm{b}, \star}$, Dario Cavallo ${ }^{\mathrm{a}, \star}$ \\ ${ }^{a}$ Department of Chemistry and Industrial Chemistry, University of Genoa, Via Dodecaneso 31, 16146, \\ Genova (Italy) \\ ${ }^{b}$ Beijing National Laboratory for Molecular Sciences, CAS Key Laboratory of Engineering Plastics, \\ Institute of Chemistry, Chinese Academy of Sciences, 100190 Beijing (China) \\ ${ }^{c}$ Beijing Key Laboratory of Clothing Materials $R$ \& D and Assessment, School of Materials Science \& \\ Engineering, Beijing Institute of Fashion Technology, 100029 Beijing (China) \\ ${ }^{d}$ Group 'Materials + Technologies' (GMT), Department of Chemical and Environmental Engineering, \\ Faculty of Engineering Gipuzkoa, University of the Basque Country (UPV/EHU), Plaza Europa 1, \\ 20018 Donostia - San Sebastian, Spain \\ ${ }^{e}$ POLYMAT and Polymer Science and Technology Department, Faculty of Chemistry, University of the \\ Basque Country UPV/EHU, Paseo Manuel de Lardizábal, 3, 20018 Donostia - San Sebastián, Spain \\ ${ }^{f}$ IKERBASQUE, Basque Foundation for Science, Bilbao, Spain \\ ${ }^{\star}$ Corresponding Authors E-mail: \\ djwang@iccas.ac.cn
}

dario.cavallo@unige.it 


\section{Abstract}

The nucleation process of poly(lactide) (PLA) on a series of fibers was studied by means of in-situ Polarized Optical Microscope (POM) during crystallization. Several synthetic and natural fibers (PLLA stereocomplex fibers (SC), PET, carbon, Kevlar, glass, hemp, linen and cellulose) were employed, and compared to customspun fiber of stereocomplex enantiomeric PLA blend.

Meaningful differences in the nucleating ability towards PLA could be found for all the considered fibers. Stereocomplex PLA fibers display extremely high nucleating efficiency, with the development of a continuous transcrystalline morphology on their surface, up to high crystallization temperatures. Quantitative measurement of the nucleation rate allowed a comparison of the different fiber substrates in the light of classical heterogeneous nucleation theory, by considering the interfacial free energy difference parameter, $\Delta \sigma$, directly related to the nucleation barrier.

The topography of the fibers surface was investigated by atomic force microscopy (AFM), and tentatively related to the measured nucleation ability. While a general effect of surface roughness on lowering the heterogeneous nucleation energy barrier can be deduced, deviations can be observed, in particular for carbon and stereocomplex PLA fibers. The different fiber wettability by PLA melt suggests that chemical interactions between the substrate and the crystallizing polymer also play 
a meaningful role in promoting the nucleation, although this aspect is generally disregarded in the literature - in favor of surface roughness. Moreover, the specific surface topography is shown to largely affect the density of available nucleation sites along the fiber.

\section{Introduction}

Fiber composites of semicrystalline polymers are able to develop, under certain conditions, a highly oriented crystalline layer with molecular chain axis parallel to fiber axis at the fiber/matrix interface. ${ }^{1-3}$ This peculiar morphology is addressed as transcrystalline layer (TCL), and is typically associated to the high nucleating ability of the embedded fibers' surface. ${ }^{4-12}$ The formation of TCL is of technological importance, because it can significantly influence the mechanical properties of the product. ${ }^{13-19}$ In fact, TCL presents a higher Young's modulus compared with the bulk materials, despite a lower strain at break. ${ }^{20,21}$ Moreover, the presence of TCL can effectively improve the adhesion between the polymer and the fiber, thus increasing the flexural modulus and strength of the composites. ${ }^{13}$

Although TCL has significant implication for the properties of fiber-reinforced composites, the exact mechanism for its development is not fully univocally ascertained. A major role in the formation of the transcrystalline layer has been

attributed to fiber's surface chemistry, ${ }^{22-24}$ topography, ${ }^{3,21}$ or residual stresses at the 
fiber/matrix interface, generated during cooling due to the mismatch in the thermal expansion coefficients of the two materials. ${ }^{4-10,25-27}$ Clearly, the transcrystalline layer forms as a consequence of extremely high surface nucleation density on the fiber, which hinders the later development of the spherulites and thus forces crystal growth to proceed perpendicular to the fiber long axis only. Therefore, understanding of fiber induced nucleation is essential.

Several detailed investigations on fiber induced nucleation have been reported. ${ }^{28,}$ ${ }^{29}$ In particular, Wang et al. ${ }^{4-10}$ investigated the nucleation of polypropylene on different fibers, including polytetrafluoroethylene (PTFE) fiber, carbon fiber, poly(p-phenylene benzobisoxazole) (PBO) fiber and Kevlar. The fiber nucleation ability was characterized on the basis of the interfacial free energy difference, $\Delta \sigma$, a parameter expressing the magnitude of the heterogeneous nucleation barrier. Moreover, such value was found to be closely correlated to the maximum temperature for transcrystalline layer formation, $T_{\max }$. Ishida and Bussi studied the crystallization phenomenon of ultrahigh-modulus polyethylene fiber reinforced polyethylene (PE) composites, finding an extremely low $\Delta \sigma$, around $0.3 \mathrm{~mJ} / \mathrm{m}^{2}$. The excellent nucleation ability was attributed to the perfect matching between the lattice parameters of the polymer/fiber system. ${ }^{29}$

However, fiber induced nucleation studies are still scarce and mainly limited to polyolefins, despite the increasing importance of bio-based polymers and composites. Poly(lactide) (PLA) is an aliphatic polyester with good 
biocompatibility and biodegradability. It has received much attention in recent years because of its potential in replacing the widely used petroleum-based polymers. ${ }^{30-40}$ There are two different enantiomeric forms of lactide, i.e., L-lactide and D-lactide, which allows preparing stereocomplexes having different properties with adjustment of L/D ratios in the synthesis mixture. ${ }^{41-43}$ Moreover, Ikada et al. reported that a blend of the poly(L-lactide) (PLLA) and poly(D-lactide) (PDLA) can develop co-crystals, containing both enantiomeric chains in the unit cell, defined as stereocomplex..$^{44-48}$ The stereocomplex crystals possess a melting temperature 40 $50{ }^{\circ} \mathrm{C}$ above that of the "homocrystals" of neat PLLA or PDLA and exhibit better mechanical properties and slower biodegradation rate. ${ }^{42,43,49-55}$ Of particular interest is the ability of stereocomplex crystals (SC) to enhance the crystallization kinetics of slow-crystallizing PLA homocrystals. It has been shown that SC surfaces can efficiently nucleate the lower melting homocrystals, although epitaxy between the two crystalline structures is probably not involved. ${ }^{17,}$ 50, 56-59 Given the higher melting point of stereocomplex crystals and their spinnability to give oriented fibers, the design of an all-poly(lactide) biobased polymer-fiber composite could be devised, possibly leading to mechanical reinforcement of the brittle PLA.

In this work, the nucleation process of poly(lactide) (PLA) on a series of fibers was studied in-situ by means of polarized optical microscope (POM). Several commercially available fibers (i.e., carbon, PET, Kevlar, and glass fibers) and natural fibers (i.e., hemp, linen and cellulose fibers) are employed and compared to 
lab-made stereocomplex enantiomeric PLA blend fibers. The nucleating efficiency of the various heterogeneous substrates was quantitatively compared on the basis of the derived interfacial free energy difference, $\Delta \sigma$, and the maximum temperature for transcrystalline layer formation, $T_{\max }$. On the basis of the results some general insights and considerations on the mechanism of fiber induced nucleation are proposed.

\section{Experimental}

\subsection{Materials and Fibers}

Samples of poly(L-lactide) (PLLA) and poly(D-lactide) (PDLA) in pellet form were kindly provided by Purac Biochem (Gorinchem, The Netherlands). PLLA sample has a molecular weight of $226 \mathrm{~kg} / \mathrm{mol}$, a melt flow index (MFI) of 6.9 $\mathrm{g} / 10 \mathrm{~min}$ and shows a nominal melting point of $175.4^{\circ} \mathrm{C}$. The SC fiber was extruded from PLLA/PDLA blend with a ratio of 1:1. Detailed information on the fiber preparation procedure and equipment can be found elsewhere..$^{59}$ After extrusion, the SC fiber was annealed at $200{ }^{\circ} \mathrm{C}$ for $1 \mathrm{~h}$, in order to obtain pure stereocomplex crystal.

As comparison, some commercial fibers (i.e., carbon, Kevlar, PET and glass fibers) and natural fibers (i.e., hemp, linen and cellulose fibers) were employed. Fibers were kindly provided by various composite and textile industries and used as 
received. Glass fibers have been previously sized, while all the other fibers did not receive any surface treatment.

\subsection{Methods}

The PLLA films were prepared by compressing PLLA pellets on a hot stage at $210{ }^{\circ} \mathrm{C}$, and the thickness of the film was adjusted to about $30-50 \mu \mathrm{m}$.

The thermal protocol adopted for sample preparation and crystallization experiments was controlled by a calibrated Mettler Toledo FP-82 microscope hotstage. A piece of PLLA thin film $(10 \mathrm{~mm} \times 10 \mathrm{~mm})$ was heated to $190{ }^{\circ} \mathrm{C}$ on a glass slide and then a single fiber was manually introduced into the film, and the single fiber-polymer composite what then covered with a microscope cover glass. The composites were then heated to $200{ }^{\circ} \mathrm{C}$ and held there for 3 min to eliminate any residual thermal-mechanical history potentially affecting the crystallization. Subsequently, the composites were cooled down to selected temperatures and allowed to crystallize for adequate time. The scheme of the temperature protocol is depicted in Figure 1. The crystallization process was observed in-situ by using a Polyvar-Pol optical microscope under crossed polarizers. Micrographs were acquired with a computer-controlled digital camera (Optika). 


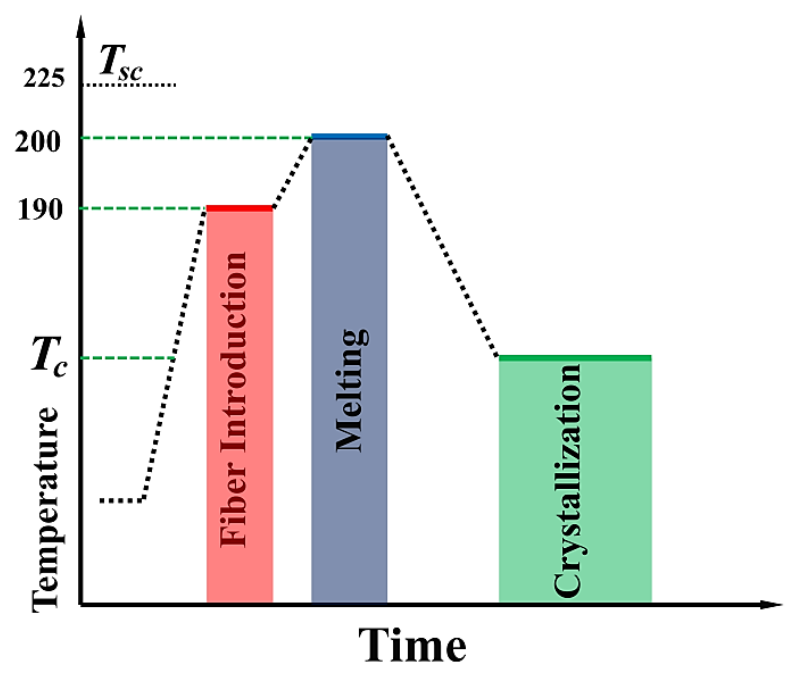

Figure 1. Schematic diagram of the applied thermal history. The melting point of SC fibers $\left(T_{s c}\right)$ is indicated by dotted lines on the y-axis.

\section{AFM characterization of fibers' surface}

In order to quantitatively characterize the surface topography of the different fiber AFM measurements have been performed. For this purpose, a Dimension Icon AFM from Bruker equipped with Nanoscope V controller was used in tapping mode. The measurements were carried out using a silicon TESP-V2 tip with $10 \mathrm{~nm}$ nominal radius and $125 \mu \mathrm{m}$ cantilever length. The operating frequency was $320 \mathrm{kHz}$ and the scan rate was between $0.4-0.7 \mathrm{~Hz} / \mathrm{s}$. AFM measurements were done with 512 scan lines and target amplitude of around 0.9 V. The representative AFM height profiles of each investigated fiber surface were extracted after second order flatten. Moreover, the root mean square roughness (RMS or $R_{q}$ ) were determined using 10 independent zones of $1 \mu \mathrm{m}^{2}$ on the fiber surface. The $R_{q}$ values were extracted from $5 \mu \mathrm{m} \times 5 \mu \mathrm{m}$ AFM height images derived after second order flatten using 
NanoScope Analysis software version 1.90.

\section{Fiber-PLA adhesion properties}

The interaction between PLA melt and the fibers surfaces was tentatively probed with contact angle measurements. Droplets of PLLA on the fibers were created according to the following procedure. SC, Kevlar, PET and glass fibers were supported on a "U-shaped" aluminum frame, and PLLA fibers (made from the same polymer used as matrix in the nucleation experiments) were tied to them at room temperature, creating several small knots. The frame was then put in an oven kept at a temperature of $210^{\circ} \mathrm{C}$, which is high enough to melt the PLLA "knots" while keeping the fibers unaffected. Several holding times in the oven were employed; an equilibrium shape of the molten PLLA droplet on the fiber was attained after 5 min. The fiber holder was then quickly extracted from the oven, and the PLLA droplet solidifies by cooling to room temperature. The contact angle of PLLA on different nucleating fibers was finally measured by using a Nordtest tensiometer, with a digital camera equipped with suitable magnifying objective to visualize the solid PLLA droplet/fiber assembly. The angles are measured on both right and left sides of the droplets and the presented results are the mean value of about 20 different droplets. 


\section{Results and Discussion}

\subsection{Morphology Investigation}

Two typical examples of time-resolved polarized optical microscopy images, acquired during the isothermal nucleation process of PLLA onto the SC and the carbon fiber are shown in Figure 2. A sporadic nucleation process can be appreciated, with the number of nuclei on the surface of both fibers increasing gradually with crystallization time. Similar nucleation process is also observed for other fibers and shown in Figure S1. The relatively low nucleation density enables one to observe the growth of the individual nuclei, which develop into distinguishable spherulites and are therefore amenable to direct counting. We note that the very different crystallization temperatures employed for the two fibers $\left(40^{\circ} \mathrm{C}\right)$ is related to the different nucleation ability. However, due to their different diameters and the different experimental time scales, the relatively nucleation efficiency cannot be grasped from the POM micrographs of Figure 2. 

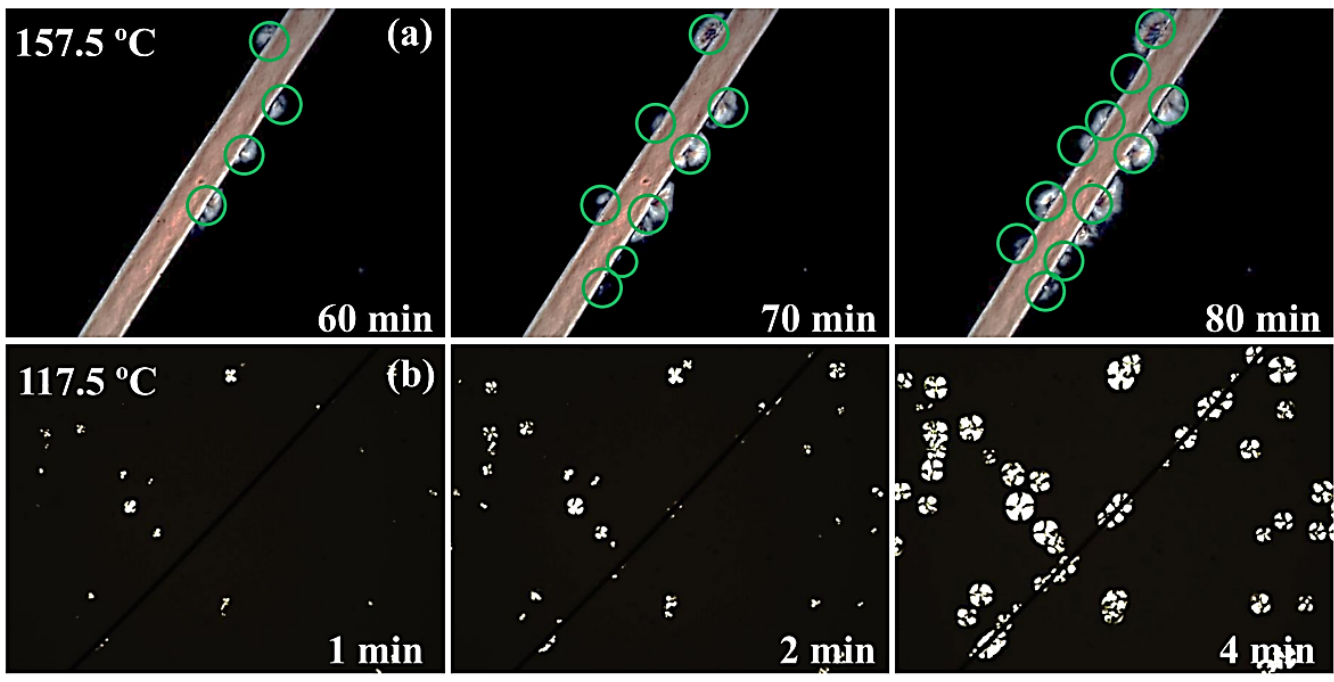

Figure 2. Optical micrographs after the indicated crystallization times for PLLA with embedded SC

fiber (a) and carbon fiber (b). Crystallization temperatures are 157.5 and $117.5{ }^{\circ} \mathrm{C}$, respectively. The PLLA spherulites in (a) are highlighted, to help visualizationand counting of the number of nucleation points . Scale bar: $100 \mu \mathrm{m}$.

The effect of crystallization temperature on nucleation can be deduced by comparing the morphology developed on the fiber surface after a given holding time at different undercoolings (Figure 3). As expected, the nucleation rate increases with decreasing crystallization temperature, as judged by the increased number of nucleated spherulites on the fiber surface at the same time. Notably, when $T_{c}$ is equal to $142.5{ }^{\circ} \mathrm{C}$ (or lower) for SC fiber and $110{ }^{\circ} \mathrm{C}$ (or lower) for carbon fiber, TCL develops as a result of the high density of nuclei on the fiber surface. In fact, when the distance between adjacent nuclei on the fiber surface is very small, the growth of crystals is spatially restricted, and the lamellae can only propagate perpendicularly to the fiber surface. We highlight the large undercooling 
dependence of the nucleation process, since the extremely different sporadic and TCL morphologies are obtained by varying the crystallization temperature of $5{ }^{\circ} \mathrm{C}$ only. Analogous results have been obtained for other commercial and natural fibers, in other specific ranges of temperatures due to intrinsically different nucleating ability (Figure S2).

Such observations are well in line with previous work on fiber induced nucleation on iso-polypropylene (i-PP) composites. ${ }^{4-10}$ For example, at $140{ }^{\circ} \mathrm{C}$, transcrystalline layer was observed for i-PP in contact with Teflon fiber, but not for i-PP/Kevlar fiber composite. The latter fiber was able to induce TCL when polypropylene crystallized at $135{ }^{\circ} \mathrm{C}^{7}$ The maximum crystallization temperature at which transcrystalline morphology could be obtained was proposed as an estimate of fiber-nucleation ability towards i-PP. ${ }^{8}$
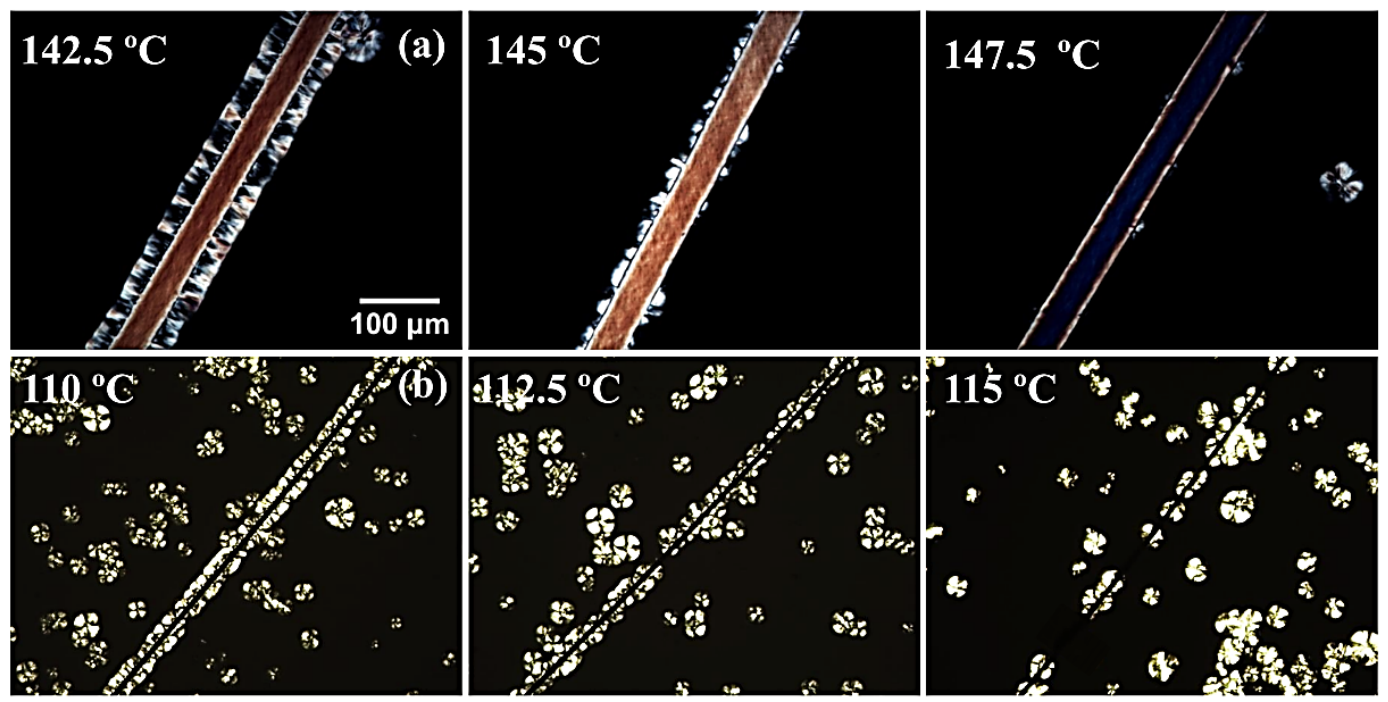

Figure 3. (a) Crystallization of PLLA on SC fiber at 142.5, 145 and $147.5{ }^{\circ} \mathrm{C}$ for $10 \mathrm{~min}$; (b) crystallization of PLLA on carbon fiber at $110,112.5$ and $115^{\circ} \mathrm{C}$ for $5 \mathrm{~min}$. 
Figure 4 compares the crystalline morphology of PLA on other different synthetic fibers (i.e., PET, Kevlar), inorganic fiber (i.e., glass) and natural fiber (i.e., hemp). The same crystallization temperature and time is considered to allow a better evaluation of nucleating efficiency of the different substrates. After $8 \mathrm{~min}$ at $130^{\circ} \mathrm{C}$, sporadically nucleated PLLA spherulites can be observed on the surfaces of carbon, PET, kevlar, glass and hemp fibers, while a clear TCL develops on SC fiber substrate. Linen and cellulose fiber display a crystalline morphology analogous to the one of hemp (not shown). A qualitative comparison of the POM micrographs in Figure 4 suggests that carbon fiber exhibits the lowest nucleating ability, and SC fiber has by far the highest, while the other substrates display intermediate nucleation efficiency. The easy development of PLA transcrystallinity on SC crystals was also evidenced by $\mathrm{Li}$ et al, who were able to change the interfacial crystallization of PLA/ramie fiber composites from sparsely dispersed spherulites to TCL, by physically decorating the surface of ramie fiber with stereocomplex crystallites adsorbed from solution. ${ }^{60}$ 

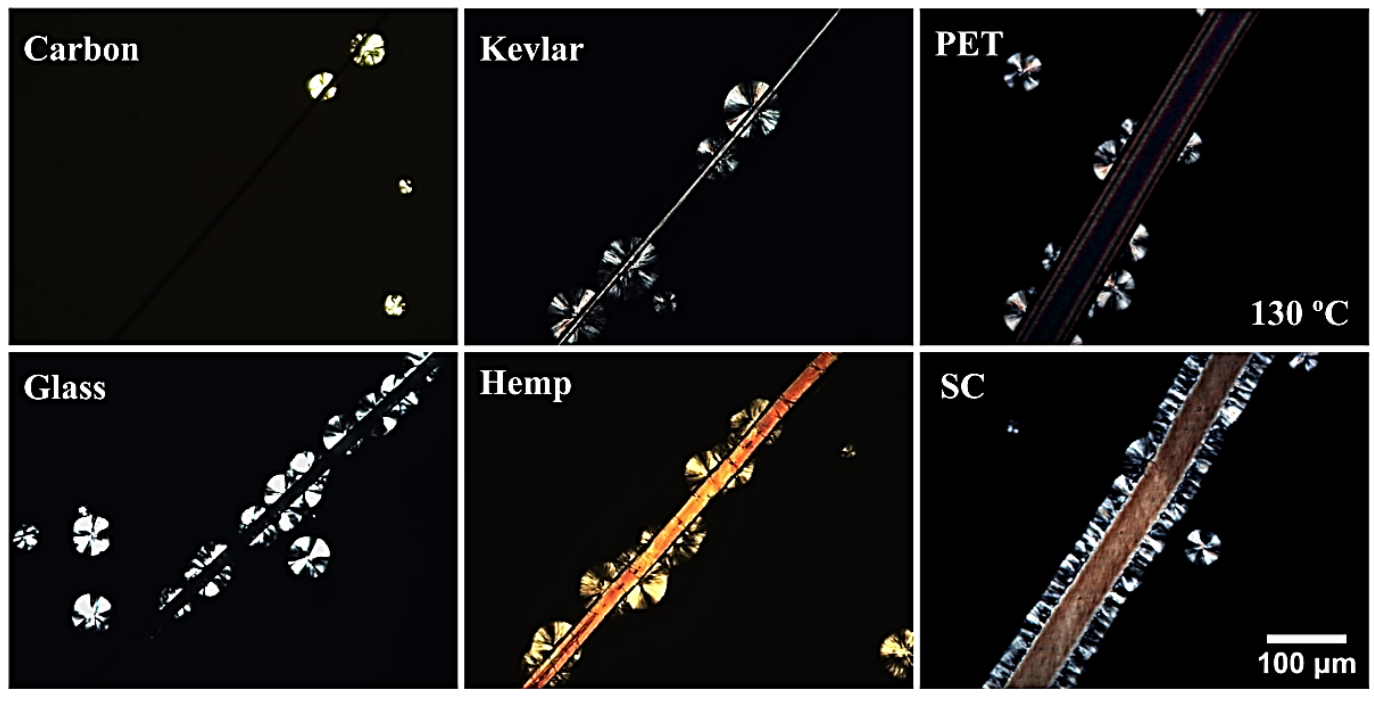

Figure 4. POM micrographs of PLLA morphology after crystallization for 8 min at $130{ }^{\circ} \mathrm{C}$ in contact

with the indicated fiber substrates.

In order to take into account the differences in the available nucleating surface, due to different fiber diameters, and the time evolution of the nucleation process, a quantitative assessment of nucleation rate at various undercooling is presented in the following section.

\subsection{Quantitative evaluation of the nucleation process of PLLA on different fiber substrates}

From optical microscopy observations, such as those shown in Figure 2, we can derive quantitative information on the nucleation kinetics on the fiber. In Figure 5(a), the number of PLLA developing spherulites per unit area of SC fiber (defined as nucleation density) is plotted as a function of time for different undercoolings. In order to calculate the nucleation density, the overall lateral surface of the fiber is 
considered, being the fiber diameter always lower than polymer sample thickness. A linear increase is observed, allowing a straightforward definition of the nucleation rate as the slope of the fitting line.

(a)

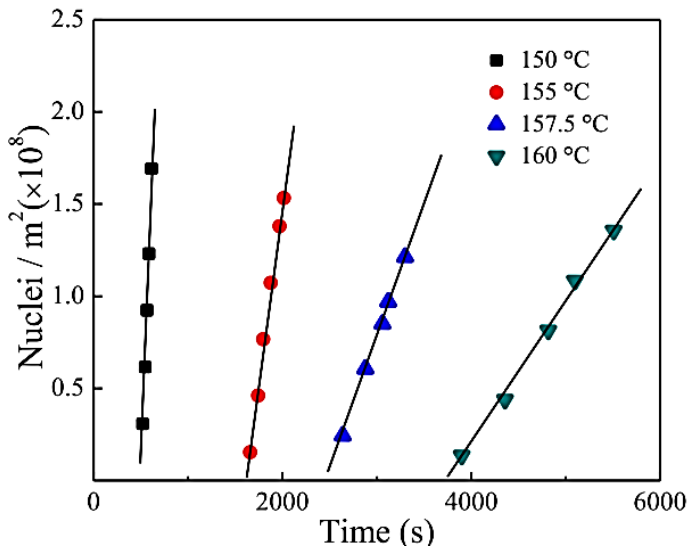

(b)

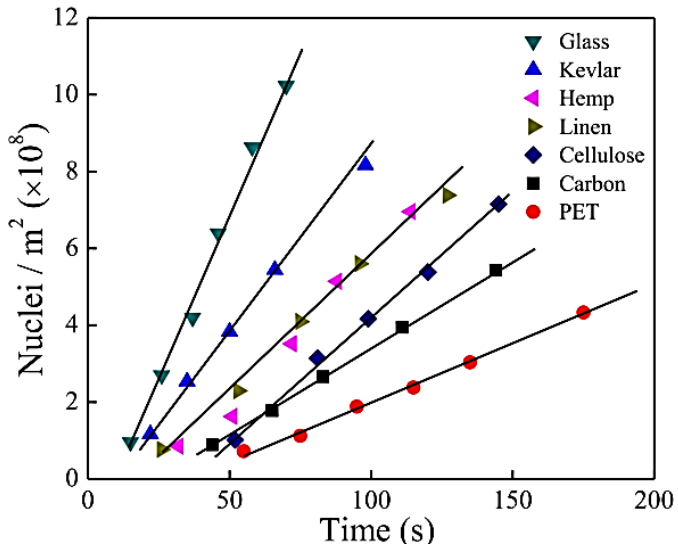

Figure 5. (a) Nucleation density of PLLA on SC fiber substrate as a function of time for specimens crystallized at the different indicated temperatures; (b) Time evolution of the nucleation density of PLLA during crystallization at $130{ }^{\circ} \mathrm{C}$, on the different indicated fibers. The displayed data are selected representative examples of the nucleation experiments.

A distinct decrease of the nucleation rate as the crystallization temperature is increased can be seen, as expected for the classical heterogeneous nucleation process, and observed in different i-PP/fiber composite in the literature. ${ }^{4-10}$ We note that, at low crystallization temperatures where the TCL develops, the direct counting of the number of nuclei is not possible. On the other hand, above a certain crystallization temperature, the nucleation density on the fibers become too low for obtaining statistically meaningful results in few experiments. The experimentally 
accessible temperature window depends on the considered fiber.

The nucleation process of PLLA on different fiber substrates are also compared for the same crystallization temperature of $130{ }^{\circ} \mathrm{C}$ in Figure 5(b). A certain difference in the nucleation rate can be appreciated, although the differences in slope are much less relevant than those observed for SC fiber at different temperatures (compare the scales of Figure 5(a) and (b)). In particular, the nucleation rate at $130{ }^{\circ} \mathrm{C}$ on PET and carbon fibers is distinctly lower than that on glass or Kevlar fiber, while all the natural fibers (hemp, linen and cellulose) are characterized by remarkably similar slopes. We note that each isothermal crystallization experiment has been repeated multiple times (at least three), and the measured nucleation rate showed a good reproducibility with relative standard deviation of the order of $10 \%$. For the sake of clarity, only representative examples of single measurements are displayed in Figure 5. Nucleation kinetics data of PLLA on the different fibers can be analyzed in light of the theory of heterogeneous nucleation. Accordingly, the nucleation rate per unit area of substrate, $I$, can be expressed by: ${ }^{61}$

$$
\begin{array}{r}
\log I=\log I_{0}-\frac{U^{*}}{2.303 R\left(T_{c}-T_{\infty}\right)} \\
-\frac{16 \sigma \sigma_{e} \Delta \sigma T_{m}^{0^{2}}}{2.303 k T_{c}\left(\Delta T \Delta h_{f} f\right)^{2}}
\end{array}
$$

The parameters appearing in equation 1 are defined as follows: $I_{0}$ is a temperature independent constant, $R$ is the gas constant, $T_{\infty}$ is the limiting temperature at which the polymer segmental motion cease ( $\left.=T_{g}-30\right), U^{*}$ is the activation energy for the 
diffusion of crystallizing elements across the phase boundary, $\Delta T$ is the undercooling (= $\left.T_{m}^{0}-T_{c}\right), T_{m}^{0}$ is equilibrium melting temperature of PLLA, $\Delta h_{f}$ is the enthalpy of fusion per unit volume of bulk crystal at $T_{m}^{0}$ and $f$ is a correction factor (= $\left.2 T_{c} /\left(T_{c}+T_{m}^{0}\right)\right)$ which describes the temperature dependence of the fusion enthalpy. $\sigma$ and $\sigma_{e}$ are the lateral and fold surface energy of the crystal/melt interfaces, while the parameter $\Delta \sigma$ is interfacial free energy difference which accounts for the substitution of a substrate/melt interface with a crystal/substrate and a crystal/melt interfaces (see later for details).

Values of $U^{*}, T_{\infty}, \Delta h_{f}$, and $\sigma \sigma_{e}$ for PLLA can be taken from the literatures as 1500 $\mathrm{cal} / \mathrm{mol}, 300 \mathrm{~K}, 111.08 \times 10^{3} \mathrm{KJ} / \mathrm{m}^{3}$ and $7.33 \times 10^{-4} \mathrm{~J}^{2} / \mathrm{m}^{4}$, respectively. ${ }^{62,} 63$ The equilibrium melting temperature of the used PLLA grade was determined by extrapolation of the observed crystal melting points measured by POM (Figure S3), as a function of crystallization temperature, according to the Hoffman-Weeks method. A value of $475 \mathrm{~K}$ is obtained, in good agreement with the literature results. ${ }^{63}$, 64

As mentioned above, $\Delta \sigma$ is defined as $\sigma_{s c}+\sigma_{c m}-\sigma_{s m}$, where $\sigma_{s c}$ is the substratecrystal interfacial free energy, $\sigma_{c m}$ is the side surface free energy of the PLLA crystal, and $\sigma_{s m}$ is the substrate-melt surface free energy. The interfacial free energy difference, $\Delta \sigma$, has commonly been used in the literature to characterize and evaluate the nucleating ability of different surfaces towards specific polymers. ${ }^{65-67}$ More specifically, this approach has been also used to characterize the nucleation activity 
of various fiber in polypropylene (PP), polyethylene (PE) and poly(caprolactone) (PCL) composites. ${ }^{4-10,28,29}$ From equation 1 , it is apparent that the lower the $\Delta \sigma$, the lower will be the energy barrier for nucleation on the given substrate, and thus the higher its nucleation ability.

In order to derive the values of $\Delta \sigma$ for the nucleation of PLLA onto different fiber, the nucleation kinetics data are analyzed and plotted in a linearized form of Equation 1 in Figure 6. The values of $\Delta \sigma$ can be determined from the slopes of the fitting lines, while the intercepts of the lines result in the determination of the parameter $I_{0}$ (see equation 1). The results for the different composites are shown in Table 1.

Figure 6(a) reveals that the data can be divided in two groups. Stereocomplex PLLA fiber is clearly the most efficient nucleating substrate. In fact, although nucleation rates values lower than the rest of the fiber were measured, these were achieved in a much lower range of undercooling, i.e., at higher crystallization temperatures. Indeed, at the crystallization temperatures which were explored for the other fibers, SC substrate always resulted in TCL formation. Moreover, the temperature dependence of the nucleation rate was distinctly the lowest among all the fibers, indicating a lower free energy barrier for nucleation on the stereocomplex crystal surface. Most of the natural and synthetic fibers presented quantitatively similar nucleation kinetics, although some differences could be appreciated by considering the most appropriate crystallization temperature region (see Figure 6(b)). Variation of more than one order of magnitude of the nucleation rates can yet 
be appreciated between for instance glass and PET fibers, or by tuning slightly the undercooling for each of the composite.

(a)

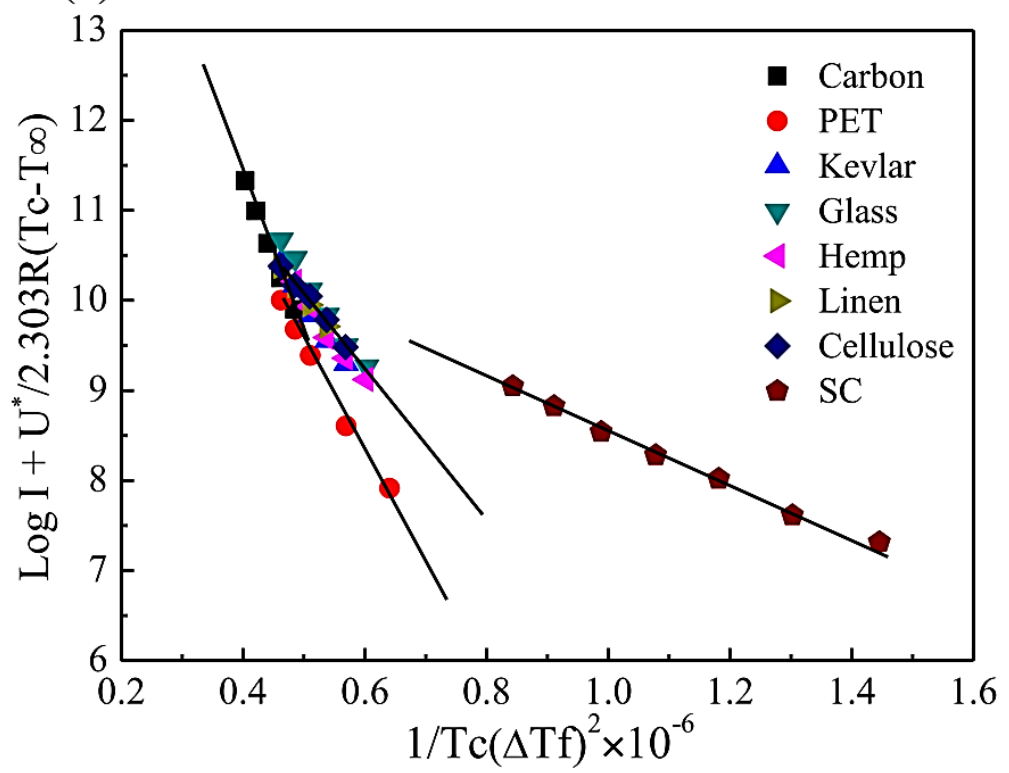

(b)

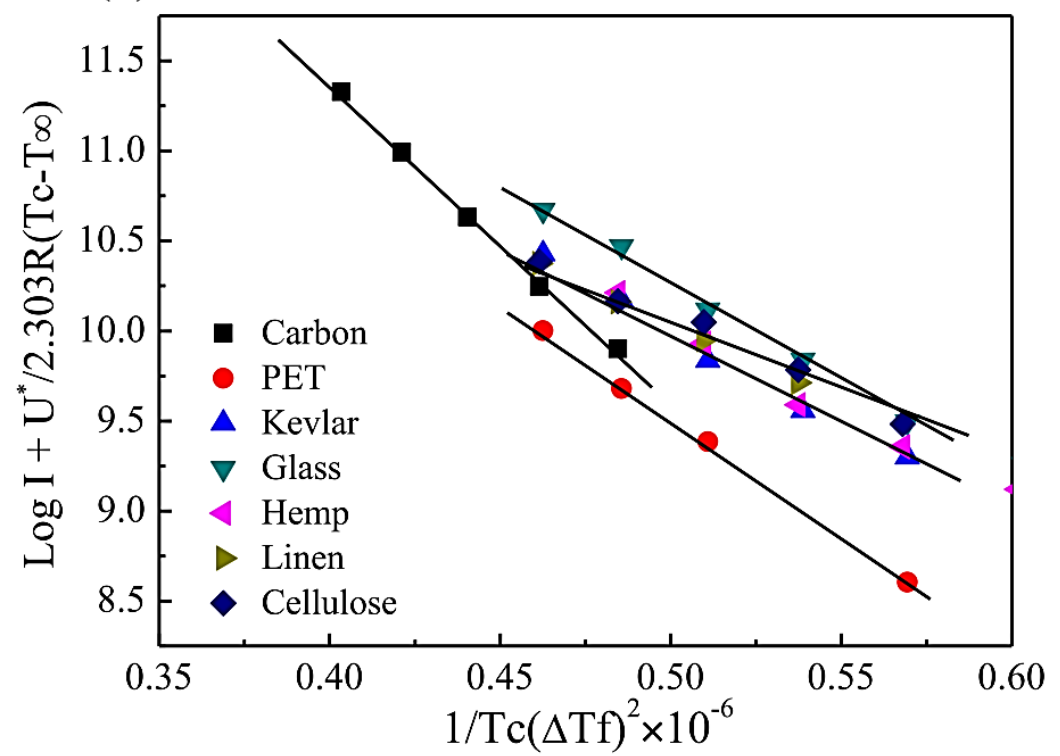

Figure 6. Variation of nucleation rate I with degree of undercooling (a), according to equation (1), to determine the interfacial free energy difference $(\Delta \sigma)$ for the different fibers; (b)enlarged view of Figure 6(a). The displayed data are average values from at least three measurements. 
From Table 1 we can appreciate that similar values of $\Delta \sigma$, ranging from about 15 to $19 \mathrm{~mJ} / \mathrm{m}^{2}$, were obtained for the majority of the investigated fibers, with two noteworthy exceptions. The interfacial free energy difference of carbon and SC fiber are in fact about 24 and $4.3 \mathrm{~mJ} / \mathrm{m}^{2}$, respectively, in agreement with the different nucleation efficiencies deduced from the POM morphological observations. We highlight that what could seem a relatively small difference in the $\Delta \sigma$ among the substrates, reflects in a very large difference in nucleation rate. In fact, the ratio between the interfacial free energy differences of the various fiber corresponds to the ratio of free energy barrier for nucleation $\left(\Delta G^{*}\right)$. Being the nucleation rate exponentially dependent on the magnitude of $\Delta G^{*}$, at a given undercooling and all the other parameters being equal, we deduce that the nucleation rate per unit area of stereocomplex PLA fiber would be, for instance, more than 80 times larger than that on the surface of the glass fiber.

The values of $\Delta \sigma$ reported hereby for the nucleation of PLLA on different fibers lay in the same range of the ones found for i-PP on a variety of fibers (4 - 16.7 $\left.\mathrm{mJ} / \mathrm{m}^{2}\right) .{ }^{8}$ In particular, SC fibers display very high nucleating activity towards PLLA, similarly to Teflon fibers for i-PP, the best substrate reported so far for that polymer.

Ishida et al. studied the nucleation of PCL and PE on ultra-high modulus polyethylene fibers, and derived the value of interfacial free energy difference by analyzing the undercooling dependence of the induction time for the appearance of the transcrystalline layer. ${ }^{28,}{ }^{29}$ Extremely low values of $\Delta \sigma$, i.e. $0.15-0.30 \mathrm{~mJ} / \mathrm{m}^{2}$ 
were obtained. However, these cases are rather peculiar. In fact, in the all-PE composite, ${ }^{29}$ due to the fact that the same crystals constitute both the fiber and the matrix, a secondary nucleation (i.e., crystal growth), rather than heterogeneous nucleation model, should more appropriately describe the phenomenon. For PE fiber in PCL matrix, the extremely low values of $\Delta \sigma$ is attributed to the existence of epitaxy among the two polymer crystals, as demonstrated by Yan et al. ${ }^{68,69}$ We recall that no epitaxial relationship has been found for PLLA $\alpha$-phase crystals and stereocomplex PLA crystal, ${ }^{59}$ thus justifying the relatively high value of interfacial free energy difference observed in the present fiber-induced nucleation experiments. The origin of the different nucleating efficiency of the various fibers is tentatively investigated in the following paragraphs.

Table 1. Fiber features (diameter and roughness) and measured PLA nucleation parameter ( $\Delta \sigma$ and $I_{0}$ from equation $1, T_{\max }$ for transcrystallinity development)

\begin{tabular}{cccccc}
\hline $\begin{array}{c}\text { Type of } \\
\text { Fiber }\end{array}$ & $\begin{array}{c}\text { Diameters } \\
(\mathrm{um})\end{array}$ & $\begin{array}{c}R_{q} \\
(\mathrm{~nm})\end{array}$ & $\begin{array}{c}\Delta \sigma \\
\left(\mathrm{mJ} / \mathrm{m}^{2}\right)\end{array}$ & $\begin{array}{c}T_{\max } \\
\left({ }^{\circ} \mathrm{C}\right)\end{array}$ & $\begin{array}{c}\log \mathrm{I}_{0} \\
\left(\text { nuclei } / \mathrm{m}^{2} \mathrm{~s}\right)\end{array}$ \\
\hline PET & 51 & 28 & 19.3 & $120 \pm 1$ & 15.4 \\
Kevlar & 12 & 12 & 19.3 & $121 \pm 1$ & 15.3 \\
Glass & 18 & 16 & 18.7 & $118 \pm 1$ & 15.4 \\
Hemp & 20 & 26 & 16.7 & $120 \pm 1$ & 14.7 \\
Linen & 23 & 32 & 15.9 & $117 \pm 1$ & 14.6
\end{tabular}




\begin{tabular}{cccccc} 
Cellulose & 12 & 32 & 14.9 & $119 \pm 1$ & 14.2 \\
Carbon & 7 & 19 & 24.1 & $108 \pm 1$ & 17.5 \\
SC & 45 & 57 & 4.3 & 142.5 & 11.5 \\
\hline
\end{tabular}

\subsection{Role of fiber surface roughness and wettability}

Surface topography, or roughness, has always been recognized to have a role in fiber-induced nucleation in polymer composites, ${ }^{7,8,21,70,71}$ and more generally, in heterogeneous nucleation. ${ }^{72-78}$ For example, a decrease in induction time and interfacial free energy difference parameter of heterogeneous nucleation was found for i-PP crystallizing in contact with copper sheets of increasing roughness (in the micrometer scale). ${ }^{74}$

In the case of fiber-induced nucleation, it can be shown via atomic force microscopy (AFM) analysis that the fiber surface is always non-uniform and small "ridges” and "valleys” are usually present. ${ }^{79}$ Such a surface topography has been suggested to enhance polymer nucleation for two possible reasons. On one hand, thermal stress develops at the fiber interface upon cooling, and might induce local orientation of polymer chain segments, providing efficient seeds for nucleation. Such thermal stresses are expected to be larger at deep "valleys" with respect to a smooth surface. ${ }^{7,10}$ On the other hand, it should be considered that the free energy barrier required to form a viable nucleus on a flat surface is always larger than that of nucleation in a groove (tertiary nucleation). ${ }^{8,61}$ As a result, such nucleation in 
surface grooves is usually preferred.

Therefore, the surface topography of the investigated fiber was probed by means of AFM, and some examples of characteristic height profiles are provided in Figure 7. Representative AFM images are reported in the Supporting Information (Figure S4). The line scans have been properly subtracted of the overall fiber curvature, as described in the Method section of the manuscript.
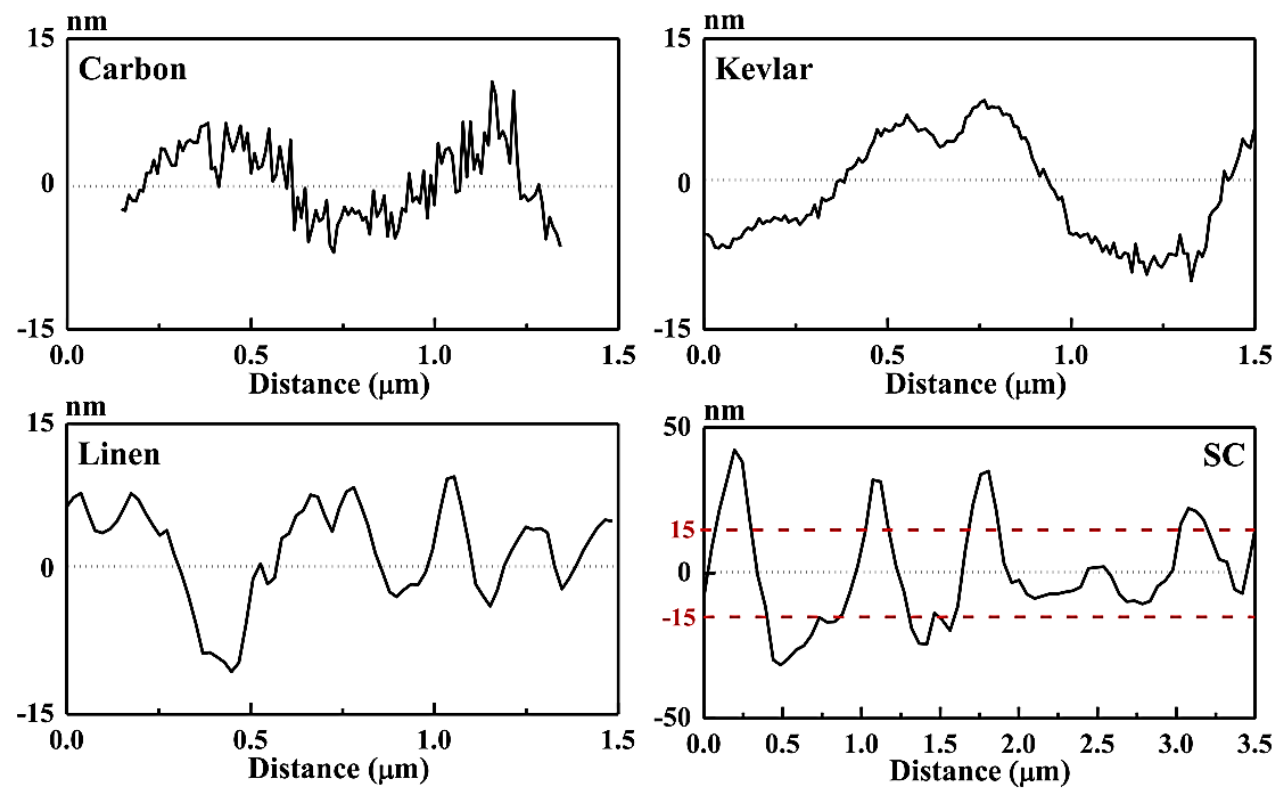

Figure 7. Examples of surface height profiles derived from analysis of AFM images. Carbon, Kevlar and Linen fibers are reported on an extended y-axis scale $(30 \mathrm{~nm})$, while the $y$-scale of the SC fiber is $100 \mathrm{~nm}$. For the sake of comparison, the height scale of the other fibers is indicated by red dashed line in the height profile plot of the SC fiber.

All the fibers present characteristic "ridges" and "valleys" features, with typical height variation below $30 \mathrm{~nm}$, with the exception of SC fibers (see Supporting Information, Figure S5 for height profiles of the additional fibers). In fact, 
stereocomplex PLA fibers present peaks on their surfaces which are characterized by a larger height variation. A particular topography is also observed in carbon fibers, in which small scale and sharp ridges and valleys occurs with high frequency, superposed to a smoother height variation of the surface.

From the height profiles as shown in Figure 7, the root mean square roughness (RMS or $R_{q}$ ) can be calculated. The values for the different fibers are reported in Table 1. Roughness values range from 12 to $32 \mathrm{~nm}$ for all the considered fibers except for stereocomplex PLA fiber, which presents an higher roughness ( $R_{q}$ equal to $57 \mathrm{~nm}$ ), as deduced from Figure 7.

From the data reported Table 1, the effect of surface roughness on the parameters of the heterogeneous nucleation model can be explored. Figure 8(a) reports the interfacial free energy difference form nucleation experiments, as a function of the fiber surface roughness. A general trend of decreasing $\Delta \sigma$ with increasing the roughness of the fiber can be appreciated, indicating that fiber-induced nucleation is favored on non-smooth fibers. This result is in agreement with the commonly proposed association of transcrystallinity development with fiber surface topography, ${ }^{4-10}$ and with the measured decrease of interfacial free energy difference for i-PP nucleation on rougher copper substrates. ${ }^{74}$

However, we note that there is no clear simple relation between $\Delta \sigma$ and $R_{q}$. In particular, carbon and stereocomplex PLA fibers deviate from the general trend, having respectively a higher and lower interfacial free energy difference than the 
one that would pertain to their surface roughness value. It should be considered that the sole mean roughness value might not be sufficient to fully characterize a complex surface topography with respect to its nucleation ability. This aspect was clearly evidenced by Lin et al., ${ }^{80}$ who showed that i-PP nucleates faster on Teflon surfaces characterized by a higher fractal dimension but lower overall roughness.

Moreover, it is expected that, for a given surface topography, interactions between the crystallizing matrix and the surface, dictated by the polymer and substrate chemistry, should also play a role in inducing nucleation. Despite the importance of the interactions via intermolecular forces between the substrates and the matrix, this role has been insufficiently documented in the literature of fiber-induced polymer crystallization, and even the absence of any surface chemistry effect on nucleation has been claimed ${ }^{21}$. On the other hand, the concept is instead rather well accepted in the nucleation of organic or inorganic molecules, especially from solution. ${ }^{77,81}$ The role of fiber matrix-interaction, or wettability, in PLLA nucleation will be tentatively addressed further on.

(a)

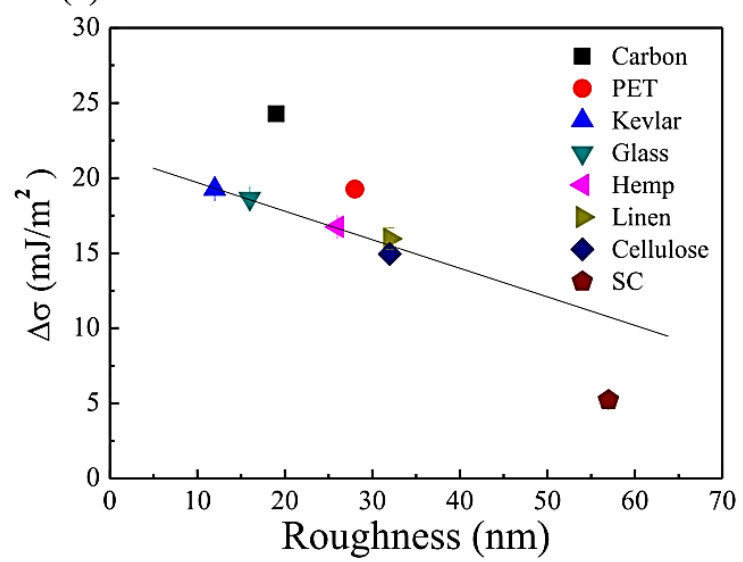

(b)

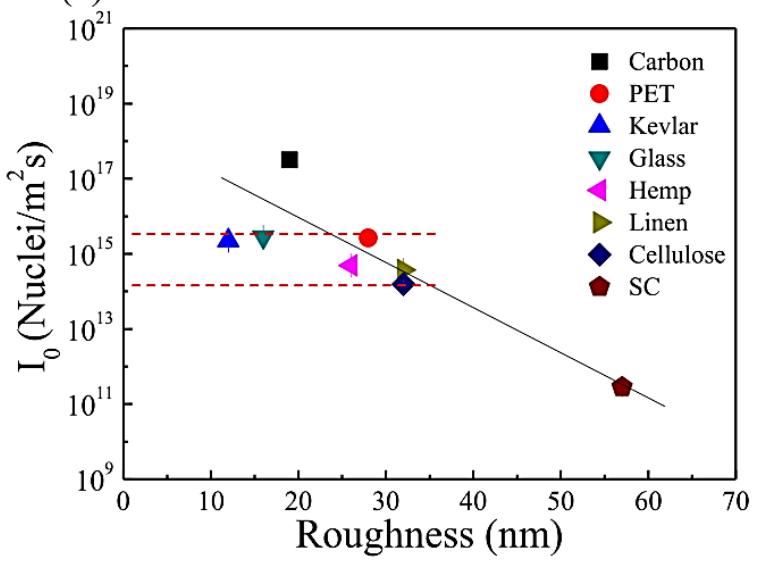


Figure 8. (a) Interfacial free energy difference, $\Delta \sigma$, and (b) Log $I_{0}$ derived from equation 1 , as a function of roughness for all the investigated fibers. The drawn lines are just a guide to the eyes.

From Figure 6, it can be deduced that the pre-exponential factor (intercept of the fitting lines with the y-axis), varies with the type of fiber. Such variation is confirmed by the data in Table 1 . The pre-exponential parameter of the nucleation rate equation $\left(I_{0}\right)$ is a temperature-independent frequency term which is commonly considered to be linked to molecular and transport properties of the nucleating material. $^{82}$

In Figure 8(b), the derived $I_{0}$ is plotted as a function of fiber surface roughness. A large variation with the type of considered fiber is apparent: while for the majority of the fibers $I_{0}$ is in the order of $10^{15}$ nuclei $/ \mathrm{m}^{2} \mathrm{~s}$, a variation of several orders of magnitude is observed for SC and carbon fibers. In particular, the lowest value is found for stereocomplex PLA fibers, while it is about $10^{6}$ times larger for carbon fiber. To the best of our knowledge, such differences in the pre-exponential factor of the heterogeneous nucleation rate equation have not been highlighted before in other studies of fiber-induced polymer nucleation.

It must be deduced that such kinetic term does not depend uniquely on the crystallizing macromolecule, but rather on the specific polymer/substrate pair. In fact, by considering that $I_{0}$ represents a frequency per unit area, it is plausible to hypothesize which it takes into account the "effective" nucleating area of the fiber. We recall that to derive the quantitative nucleation rate data, the macroscopic area 
of the fiber has been considered. Therefore, from the measured value of $I_{0}$, we must deduce that the carbon fiber possesses a much higher density of "potentially active" nucleation sites on his surface, with respect to that of stereocomplex PLA fiber. This notwithstanding, the overall nucleation kinetics might be lower, due to the higher energy barrier term (related to the value of $\Delta \sigma$ ). However, the definition of an "active nucleation site" remains elusive, and it must be linked to the matching between the critical nucleus size at a certain undercooling and the exact surface topography. We can thus speculate that the successions of ridges and valleys at that specific length scale in the carbon fiber provides abundant preferred nucleation sites for PLLA. In contrast the SC fiber, despite possessing a much higher average roughness, has fewer active sites due to the lack of grooves of adequate size.

Despite the interesting correlations found between nucleation kinetics parameters and surface roughness, it has been recognized in the studies of heterogeneous nucleation that molecule-substrate interactions are of great importance. A straightforward way to quantify these interactions is the characterization of the substrate wettability by the crystallizing substance, by means of contact angle measurements. In fact, Turnbull used the melt-substrate contact angle to compute the decrease in the free energy barrier for heterogeneous nucleation with respect to the homogeneous case. ${ }^{83}$ Experimentally, contact angle measurements have proven to closely correlate with the nucleation ability of solid substrates in the crystallization of small molecules from solution or melt, ${ }^{77,81}$ including the case of 
water freezing. ${ }^{84}$ More recently, the same concept has been shown also for poly(butylene succinate) (PBS), which shows a smaller contact angle on hexagonal boron nitride nanosheets with respect to graphene, in agreement with the lower nucleating effect of the latter substrate. ${ }^{85}$

Accordingly, we attempted to carry out PLLA wettability of the different fibers, by creating polymer droplets on their surface, according to the method described in the experimental section of the manuscript (see Figure S6 of the Supporting Information for representative photographs of sample preparation). Given the similar nucleation activity found for the majority of the fibers, we focused on the synthetic ones, which were more easily handled. Unfortunately, measurement on carbon fiber could not be performed due to its excessive brittleness.

Figure 9 shows the typical droplet shapes obtained by melting the PLLA matrix on different fiber substrates. A very similar shape is found for all the commercial fibers, characterized by a droplet/fiber contact angle of around $55^{\circ}$, a value denoting an appreciable wettability.

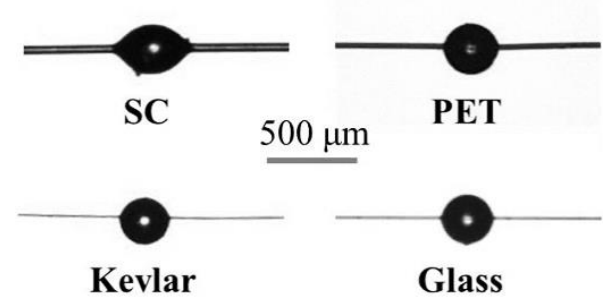

Figure 9. Optical micrographs showing the wettability of different fibers by PLLA.

A very different droplet shape is observed for PLLA/SC fiber. In this system PLLA definitely wets the fiber much more, with a contact angle equal to about $40^{\circ}$. 
The higher wettability of PLA SC fibers by the PLLA matrix is reasonably explained by considering a low interfacial tension between the two, due to the identical chemical nature. Although we are aware of the possible effect of surface roughness on the measured contact angle value, we hypothesize that an important role may be played by the favorable intermolecular interactions, since no distinct variation of the contact angle is seen for the other synthetic fibers, despite the measurable difference in surface roughness (Table 1). Therefore, also in the case of PLLA fiber-induced nucleation, wettability measurements are found to correlate well with the observed nucleation efficiencies of the substrates. As such, this simple method is likely to provide reliable information on fiber-induced nucleation and could potentially be extended to other relevant polymer composites.

\subsection{Maximum temperature for transcrystalline layer development}

For a given fiber, there is a maximum crystallization temperature $\left(T_{\max }\right)$ at which a continuous transcrystalline layer develops. Any crystallization temperature below $T_{\max }$ will result in TCL morphology, while for $T>T_{\max }$ sporadic nucleation occurs. It has been shown for i-PP/fiber composites, that such $T_{\max }$ is related to the interfacial free energy difference: the lower $\Delta \sigma$, the higher $T_{\max }$, given the lower free energy barrier that need to be overcome to form a viable nucleus on the fiber surface. ${ }^{8}$

The values of $T_{\max }$ obtained for the investigated fibers are reported in Table 1 , and 
displayed as a function of $\Delta \sigma$ in Figure 10(a). A general linear correlation can be seen, analogously to that reported for i-PP. With the variation of $\Delta \sigma$ from 24.1 to 4.3 $\mathrm{mJ} / \mathrm{m}^{2}, T_{\max }$ increases of more than $30{ }^{\circ} \mathrm{C}$, from $108{ }^{\circ} \mathrm{C}$ for carbon fiber to $142{ }^{\circ} \mathrm{C}$ for stereocomplex fiber. Thus, also for PLLA, the parameter $T_{\max }$ provides a measure of the nucleating ability of a given fiber.

(a)

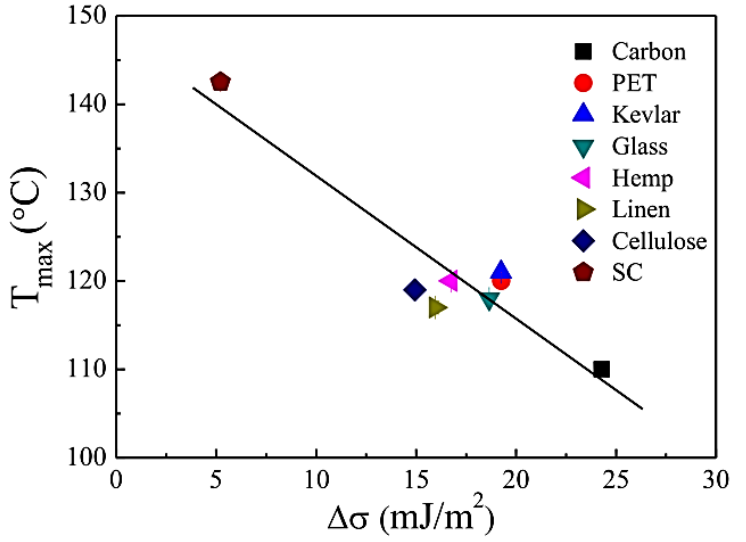

(b)

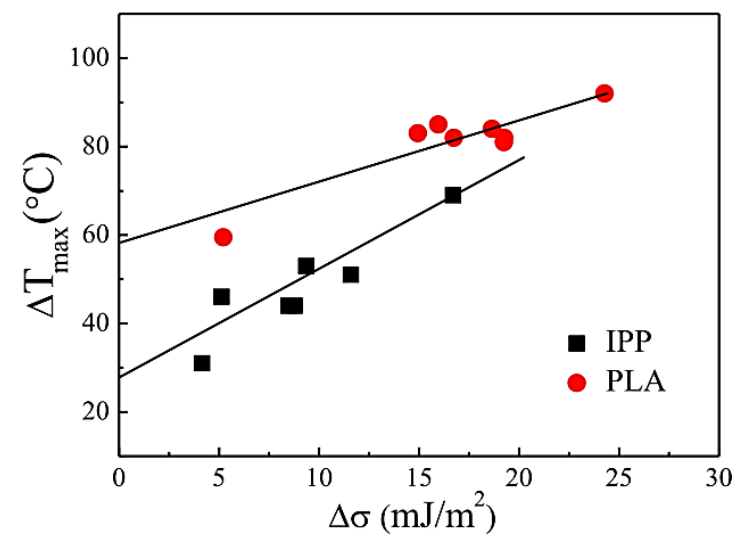

Figure 10. (a) $T_{\max }$ for TCL development in the various fiber as a function of $\Delta \sigma$ values; (b) Comparison of the data in 8(a) with literature data for $\mathrm{i}-P P .^{8}$ In this case, the undercooling is correlated with the $\Delta \sigma$, for a more direct visualization of the different polymers.

It is worthwhile to compare the behavior of PLLA with published results of i-PP. ${ }^{8}$ However, given the different crystallization temperature range which characterizes the two polymers, instead of the maximum temperature for TCL development, the corresponding undercooling $\left(\Delta T_{\max }\right)$ is considered, taking into account the equilibrium melting point of PLLA and i-PP. The results are shown in Figure 10(b). It can be seen that for a given interfacial free energy difference $\Delta \sigma$, much higher undercoolings are required to grow a transcrystalline morphology in PLLA, with 
respect to i-PP. Since $\Delta \sigma$ takes into account the free energy required to nucleate a monolayer of the crystal in contact with the fiber surface, we might deduce that the TCL formation is not completely controlled by this step of the nucleation process, i.e., the growth of further crystalline layers on top of the first one, up to the attainment of a nucleus of supercritical sizes must be the controlling factor. This different energy barrier is related to the energetics of secondary nucleation and chain diffusion, and is indeed expected to be different, depending on the considered semicrystalline polymer.

\section{Conclusion}

The nucleating ability of different fibers towards PLLA was successfully described with a classical heterogeneous nucleation model, and the observed differences could be quantified in terms of the interfacial free energy difference, $\Delta \sigma$. Among all the considered synthetic and natural fibers, stereocomplex PLA fibers show by far the highest nucleating efficiency. A general trend of decreasing $\Delta \sigma$ with the increase of surface roughness could be grasped, although carbon and SC fibers displayed relevant deviations.

Thus, we can infer that roughness cannot be considered the sole or most important parameter which contributes in determining the nucleating efficiency of fibers in polymer composites, as often assumed in the literature. In fact, the different wetting 
behavior of the fiber by PLA melt, suggests that chemical interactions between the fiber and the polymer, can also be of importance. Moreover, the surface topography/roughness is suggested to affect the availability of active nucleation sites on the fiber surface, as deduced by the largely different nucleation preexponential factors, $I_{0}$, measured for the various fibers. Finally, a clear relationship between $\Delta \sigma$ and $T_{\max }$, the maximum crystallization temperature at which a transcrystalline layer could be induced, was also observed.

This work extends the classical studies of fiber-induced nucleation and transcrystallinity in composites to a different polymer-fiber system, and highlights some open issues which need to be addressed for a comprehensive understanding of the heterogeneous nucleation of polymer crystals on natural and synthetic fibers.

\section{Acknowledgements}

BW thanks the China Scholarship Council (CSC) for funding his Ph.D scholarship. All authors gratefully acknowledge the support of the EU through the H2020-MSCA-RISE-2017-778092 BIODEST project. AJM acknowledges financial support from Spanish Ministry of Science, Innovation and Universities (MAT2017-83014-C2-1-P)

\section{Supporting Information}

Optical micrographs of different PLL/ fiber samples after crystallization at $125{ }^{\circ} \mathrm{C}$ for 
different time ; Optical micrographs of PLLA after crystallization on different fiber surfaces at given temperatures and times; Equilibrium melting point of PLLA derived from the Hoffman-Weeks's extrapolation methods; AFM height images of different fiber surfaces; Surface height profiles derived from the analysis of AFM images; Optical micrographs of PLLA fiber knot on SC fiber at room temperature and after melt annealing

\section{Reference}

1. Quan, H.; Li, Z.-M.; Yang, M.-B.; Huang, R. On transcrystallinity in semi-crystalline polymer composites. Composites Science and Technology 2005, 65 (7-8), 999-1021.

2. ZHENG, H.-l.; LIU, Z.-z.; LI, C.-y.; LU, B.; ZHENG, G.-q. A Review on Crystalline Behaviors of Semi-crystalline Polymer/Carbon Nanotubes Nanocomposites. Shanghai Plastics 2013, (2), 3.

3. Huson, M.; McGill, W. Transcrystallinity in polypropylene. Journal of Polymer Science: Polymer Chemistry Edition 1984, 22 (11), 3571-3580.

4. Wang, C.; Hwang, L. Transcrystallization of PTFE fiber/PP composites (I) crystallization kinetics and morphology. Journal of Polymer Science Part B: Polymer Physics 1996, 34 (1), 47-56.

5. Wang, C.; Wu, Y.-J.; Fang, C.-Y.; Tsai, C.-W. Electrospun nanofiber-reinforced polypropylene composites: Nucleating ability of nanofibers. Composites Science and Technology 2016, 126, 1-8.

6. Wang, C.; Liu, C. Transcrystallization of polypropylene on carbon fibres. Polymer 1997, 38 (18), 4715-4718. 
7. Wang, C.; Liu, C.-R. Transcrystallization of polypropylene composites: nucleating ability of fibres. Polymer 1999, 40 (2), 289-298.

8. Wang, C.; Liu, F.-H.; Huang, W.-H. Electrospun-fiber induced transcrystallization of isotactic polypropylene matrix. Polymer 2011, 52 (5), 1326-1336.

9. Wang, C.; Fang, C.-Y.; Wang, C.-Y. Electrospun poly (butylene terephthalate) fibers: Entanglement density effect on fiber diameter and fiber nucleating ability towards isotactic polypropylene. Polymer 2015, 72, 21-29.

10. Wang, C.; Liu, C.; Chen, C.; Hawang, L. Transcrystallinity in PTFE fiber/PP composites. The Journal of Adhesion 1998, 67 (1-4), 167-180.

11. He, C.; Dong, X.; Zhang, X.; Wang, D.; Xu, D. Morphology investigation of transcrystallinity at polyamide 66/aramid fiber interface. Journal of applied polymer science 2004, 91 (5), 2980-2983.

12. Shi, H.; Zhao, Y.; Dong, X.; He, C.; Wang, D.; Xu, D. Transcrystalline morphology of nylon 6 on the surface of aramid fibers. Polymer international 2004, 53 (11), 1672-1676.

13. Folkes, M.; Hardwick, S. The mechanical properties of glass/polypropylene multilayer laminates. Journal of Materials Science 1990, 25 (5), 2598-2606.

14. Kwei, T.; Schonhorn, H.; Frisch, H. Dynamic mechanical properties of the transcrystalline regions in two polyolefins. Journal of Applied Physics 1967, 38 (6), 25122516.

15. Qin, Y.; Xu, Y.; Zhang, L.; Zheng, G.; Yan, X.; Dai, K.; Liu, C.; Shen, C.; Guo, Z. Interfacial interaction enhancement by shear-induced $\beta$-cylindrite in isotactic 
polypropylene/glass fiber composites. Polymer 2016, 100, 111-118.

16. Qin, Y.; Xu, Y.; Zhang, L.; Zheng, G.; Dai, K.; Liu, C.; Yan, X.; Guo, J.; Guo, Z. Shearinduced interfacial sheath structure in isotactic polypropylene/glass fiber composites. Polymer 2015, 70, 326-335.

17. Saeidlou, S.; Huneault, M. A.; Li, H.; Sammut, P.; Park, C. B. Evidence of a dual network/spherulitic crystalline morphology in PLA stereocomplexes. Polymer 2012, 53 (25), 5816-5824.

18. Gao, T.; Zhao, S.-J.; Bao, R.-Y.; Zhong, G.-J.; Li, Z.-M.; Yang, M.-B.; Yang, W. Constructing Sandwich-Architectured Poly (L-lactide)/High-Melting-Point Poly (L-lactide) Non-Woven Fabrics: Towards Heat Resistant Poly (L-lactide) Barrier Biocomposites with Full Biodegradability. ACS Applied Bio Materials 2019.

19. Gao, T.; Zhang, Z.-M.; Li, L.; Bao, R.-Y.; Liu, Z.-Y.; Xie, B.-H.; Yang, M.-B.; Yang, W. Tailoring Crystalline Morphology by High-Efficiency Nucleating Fiber: Toward HighPerformance Poly (l-lactide) Biocomposites. ACS applied materials \& interfaces 2018, 10 (23), 20044-20054.

20. Zhao, R.; Zhou, X.; Dai, G. Effect of the microstructure of GMT on its mechanical properties. Polymer composites 2002, 23 (6), 1026-1035.

21. Hata, T.; Ohsaka, K.; Yamada, T.; Nakamae, K.; Shibata, N.; Matsumoto, T. Transcrystalline region of polypropylene: its formation, structure and mechanical properties. The Journal of Adhesion 1994, 45 (1-4), 125-135.

22. Wen, T.; Liu, G.; Zhou, Y.; Zhang, X.; Wang, F.; Chen, H.; Loos, J.; Wang, D. Epitaxy- 
induced crystallization of olefin block copolymers. Macromolecules 2012, 45 (15), 59795985.

23. Guo, Z.; Li, S.; Liu, X.; Zhang, J.; Li, H.; Sun, X.; Ren, Z.; Yan, S. Epitaxial crystallization of isotactic poly (methyl methacrylate) from different states on highly oriented polyethylene thin film. The Journal of Physical Chemistry B 2018, 122 (40), 94259433.

24. Liu, J.; Wang, J.; Li, H.; Shen, D.; Zhang, J.; Ozaki, Y.; Yan, S. Epitaxial crystallization of isotactic poly (methyl methacrylate) on highly oriented polyethylene. The journal of physical chemistry B 2006, 110 (2), 738-742.

25. Thomason, J.; Van Rooyen, A. Transcrystallized interphase in thermoplastic composites. Journal of materials science 1992, 27 (4), 897-907.

26. Cho, K.; Kim, D.; Yoon, S. Effect of substrate surface energy on transcrystalline growth and its effect on interfacial adhesion of semicrystalline polymers. Macromolecules 2003, 36 (20), 7652-7660.

27. Gray, D. “Transcrystallization” induced by mechanical stress on a polypropylene melt. Journal of Polymer Science: Polymer Letters Edition 1974, 12 (11), 645-650.

28. Ishida, H.; Bussi, P. Induction time approach to surface induced crystallization in polyethylene/poly ( $\varepsilon$-caprolactone) melt. Journal of materials science 1991, 26 (23), 63736382.

29. Ishida, H.; Bussi, P. Surface induced crystallization in ultrahigh-modulus polyethylene fiber-reinforced polyethylene composites. Macromolecules 1991, 24 (12), 3569-3577. 
30. Nampoothiri, K. M.; Nair, N. R.; John, R. P. An overview of the recent developments in polylactide (PLA) research. Bioresource technology 2010, 101 (22), 8493-8501.

31. Murdoch, J. R.; Loomis, G. L., Polylactide compositions. Google Patents: 1988.

32. Loomis, G. L.; Murdoch, J. R., Polylactide compositions. Google Patents: 1991.

33. Conn, R.; Kolstad, J.; Borzelleca, J.; Dixler, D.; Filer Jr, L.; LaDu Jr, B.; Pariza, M. Safety assessment of polylactide (PLA) for use as a food-contact polymer. Food and Chemical Toxicology 1995, 33 (4), 273-283.

34. Witzke, D. R. Introduction to properties, engineering, and prospects of polylactide polymers. 1999.

35. Xu, H.; Teng, C.; Yu, M. Improvements of thermal property and crystallization behavior of PLLA based multiblock copolymer by forming stereocomplex with PDLA oligomer. Polymer 2006, 47 (11), 3922-3928.

36. Gupta, B.; Revagade, N.; Hilborn, J. Poly (lactic acid) fiber: An overview. Progress in polymer science 2007, 32 (4), 455-482.

37. Rasal, R. M.; Janorkar, A. V.; Hirt, D. E. Poly (lactic acid) modifications. Progress in polymer science 2010, 35 (3), 338-356.

38. Liu, H.; Zhang, J. Research progress in toughening modification of poly (lactic acid). Journal of polymer science part B: Polymer Physics 2011, 49 (15), 1051-1083.

39. Zhang, J.; Duan, Y.; Sato, H.; Tsuji, H.; Noda, I.; Yan, S.; Ozaki, Y. Crystal modifications and thermal behavior of poly (L-lactic acid) revealed by infrared spectroscopy. Macromolecules 2005, 38 (19), 8012-8021. 
40. Xiao, L.; Wang, B.; Yang, G.; Gauthier, M., Poly (lactic acid)-based biomaterials: synthesis, modification and applications. InTech: 2012.

41. Tsuji, H.; Horii, F.; Hyon, S. H.; Ikada, Y. Stereocomplex formation between enantiomeric poly (lactic acid) s. 2. Stereocomplex formation in concentrated solutions. Macromolecules 1991, 24 (10), 2719-2724.

42. Wei, X.-F.; Bao, R.-Y.; Cao, Z.-Q.; Yang, W.; Xie, B.-H.; Yang, M.-B. Stereocomplex crystallite network in asymmetric PLLA/PDLA blends: Formation, structure, and confining effect on the crystallization rate of homocrystallites. Macromolecules 2014, 47 (4), 14391448.

43. Jing, Z.; Shi, X.; Zhang, G. Competitive stereocomplexation and homocrystallization behaviors in the poly (lactide) blends of PLLA and PDLA-PEG-PDLA with controlled block length. Polymers 2017, 9 (3), 107.

44. Ikada, Y.; Jamshidi, K.; Tsuji, H.; Hyon, S. H. Stereocomplex formation between enantiomeric poly (lactides). Macromolecules 1987, 20 (4), 904-906.

45. Tsuji, H.; Hyon, S. H.; Ikada, Y. Stereocomplex formation between enantiomeric poly (lactic acid) s. 4. Differential scanning calorimetric studies on precipitates from mixed solutions of poly (D-lactic acid) and poly (L-lactic acid). Macromolecules 1991, 24 (20), 5657-5662.

46. Tsuji, H.; Ikada, Y.; Hyon, S. H.; Kimura, Y.; Kitao, T. Stereocomplex formation between enantiomeric poly (lactic acid). VIII. Complex fibers spun from mixed solution of poly (D - lactic acid) and poly (L - lactic acid). Journal of applied polymer science 1994, 
$51(2), 337-344$.

47. Tsuji, H.; Horii, F.; Nakagawa, M.; Ikada, Y.; Odani, H.; Kitamaru, R. Stereocomplex formation between enantiomeric poly (lactic acid) s. 7. Phase structure of the stereocomplex crystallized from a dilute acetonitrile solution as studied by high-resolution solid-state carbon-13 NMR spectroscopy. Macromolecules 1992, 25 (16), 4114-4118.

48. Tsuji, H.; Ikada, Y. Stereocomplex formation between enantiomeric poly (lactic acid) s. XI. Mechanical properties and morphology of solution-cast films. Polymer 1999, 40 (24), 6699-6708.

49. Fan, Y.; Nishida, H.; Shirai, Y.; Tokiwa, Y.; Endo, T. Thermal degradation behaviour of poly (lactic acid) stereocomplex. polymer Degradation and Stability 2004, 86 (2), 197208.

50. Rahman, N.; Kawai, T.; Matsuba, G.; Nishida, K.; Kanaya, T.; Watanabe, H.; Okamoto, H.; Kato, M.; Usuki, A.; Matsuda, M. Effect of polylactide stereocomplex on the crystallization behavior of poly (L-lactic acid). Macromolecules 2009, 42 (13), 4739-4745. 51. Sun, J.; Yu, H.; Zhuang, X.; Chen, X.; Jing, X. Crystallization behavior of asymmetric PLLA/PDLA blends. The Journal of Physical Chemistry B 2011, 115 (12), 2864-2869.

52. Hirata, M.; Kimura, Y. Thermomechanical properties of stereoblock poly (lactic acid) s with different PLLA/PDLA block compositions. Polymer 2008, 49 (11), 2656-2661.

53. Shao, J.; Xiang, S.; Bian, X.; Sun, J.; Li, G.; Chen, X. Remarkable melting behavior of PLA stereocomplex in linear PLLA/PDLA blends. Industrial \& Engineering Chemistry Research 2015, 54 (7), 2246-2253. 
54. Sarasua, J.; Arraiza, A. L.; Balerdi, P.; Maiza, I. Crystallinity and mechanical properties of optically pure polylactides and their blends. Polymer Engineering \& Science 2005, 45 (5), 745-753.

55. Tsuji, H. Poly (lactide) stereocomplexes: formation, structure, properties, degradation, and applications. Macromolecular bioscience 2005, 5 (7), 569-597.

56. Tsuji, H.; Takai, H.; Saha, S. K. Isothermal and non-isothermal crystallization behavior of poly (L-lactic acid): Effects of stereocomplex as nucleating agent. Polymer 2006, 47 (11), 3826-3837.

57. Schmidt, S. C.; Hillmyer, M. A. Polylactide stereocomplex crystallites as nucleating agents for isotactic polylactide. Journal of Polymer Science Part B: Polymer Physics 2001, 39 (3), 300-313.

58. Anderson, K. S.; Hillmyer, M. A. Melt preparation and nucleation efficiency of polylactide stereocomplex crystallites. Polymer 2006, 47 (6), 2030-2035.

59. Wen, T.; Xiong, Z.; Liu, G.; Zhang, X.; de Vos, S.; Wang, R.; Joziasse, C. A.; Wang, F.; Wang, D. The inexistence of epitaxial relationship between stereocomplex and $\alpha$ crystal of poly (lactic acid): Direct experimental evidence. Polymer 2013, 54 (7), 1923-1929.

60. Liang, Y.-Y.; Xu, J.-Z.; Li, Y.; Zhong, G.-J.; Wang, R.; Li, Z.-M. Promoting Interfacial Transcrystallization in Polylactide/Ramie Fiber Composites by Utilizing Stereocomplex Crystals. ACS Sustainable Chemistry \& Engineering 2017, 5 (8), 7128-7136.

61. Wunderlich, B. Macromolecular Physics, Vol. 2, Crystal Nucleation. Growth, Annealing 1976. 
62. Kalb, B.; Pennings, A. General crystallization behaviour of poly (L-lactic acid). Polymer 1980, 21 (6), 607-612.

63. Vasanthakumari, R.; Pennings, A. Crystallization kinetics of poly (L-lactic acid). Polymer 1983, 24 (2), 175-178.

64. Müller, A. J.; Ávila, M.; Saenz, G.; Salazar, J., Crystallization of PLA-based Materials, Chapter 3 in Poly(lactic acid) Science and Technology: Processing, Properties, Additives and Applications. Royal Society of Chemistry: 2014.

65. Chatterjee, A.; Price, F.; Newman, S. Heterogeneous nucleation of crystallization of high polymers from the melt. I. Substrate - induced morphologies. Journal of Polymer Science: Polymer Physics Edition 1975, 13 (12), 2369-2383.

66. Chatterjee, A.; Price, F.; Newman, S. Heterogeneous nucleation of crystallization of high polymers from the melt. II. Aspects of transcrystallinity and nucleation density. Journal of Polymer Science: Polymer Physics Edition 1975, 13 (12), 2385-2390.

67. Chatterjee, A.; Price, F.; Newman, S. Heterogeneous nucleation of crystallization of high polymers from the melt. III. Nucleation kinetics and interfacial energies. Journal of Polymer Science: Polymer Physics Edition 1975, 13 (12), 2391-2400.

68. Yan, C.; Li, H.; Zhang, J.; Ozaki, Y.; Shen, D.; Yan, D.; Shi, A.-C.; Yan, S. Surfaceinduced anisotropic chain ordering of polycarprolactone on oriented polyethylene substrate: Epitaxy and soft epitaxy. Macromolecules 2006, 39 (23), 8041-8048.

69. Chang, H.; Zhang, J.; Li, L.; Wang, Z.; Yang, C.; Takahashi, I.; Ozaki, Y.; Yan, S. A study on the epitaxial ordering process of the polycaprolactone on the highly oriented 
polyethylene substrate. Macromolecules 2009, 43 (1), 362-366.

70. Sukhanova, T.; Lednický, F.; Urban, J.; Baklagina, Y.; Mikhailov, G.; Kudryavtsev, V. Morphology of melt crystallized polypropylene in the presence of polyimide fibres. Journal of materials science 1995, 30 (9), 2201-2214.

71. Wang, C.; Liu, C. R. Transcrystallization of PTFE fiber/PP composites-III. Effect of fiber pulling on the crystallization kinetics. Journal of Polymer Science Part B: Polymer Physics 1998, 36 (8), 1361-1370.

72. Wittmann, J. C.; Smith, P. Highly oriented thin films of poly (tetrafluoroethylene) as a substrate for oriented growth of materials. Nature 1991, 352 (6334), 414.

73. Damman, P.; Coppée, S.; Geskin, V. M.; Lazzaroni, R. What is the mechanism of oriented crystal growth on rubbed polymer substrates? Topography vs epitaxy. Journal of the American Chemical Society 2002, 124 (51), 15166-15167.

74. Lin, C.; Ding, S.; Hwang, Y. Interfacial crystallization of isotactic polypropylene molded against the copper surface with various surface roughnesses prepared by an electrochemical process. Journal of materials science 2001, 36 (20), 4943-4948.

75. Page, A. J.; Sear, R. P. Crystallization controlled by the geometry of a surface. Journal of the American Chemical Society 2009, 131 (48), 17550-17551.

76. Liu, Y.-X.; Wang, X.-J.; Lu, J.; Ching, C.-B. Influence of the roughness, topography, and physicochemical properties of chemically modified surfaces on the heterogeneous nucleation of protein crystals. The Journal of Physical Chemistry B 2007, 111 (50), 1397113978. 
77. Di Profio, G.; Fontananova, E.; Curcio, E.; Drioli, E. From tailored supports to controlled nucleation: Exploring material chemistry, surface nanostructure, and wetting regime effects in heterogeneous nucleation of organic molecules. Crystal Growth \& Design 2012, 12 (7), 3749-3757.

78. Holbrough, J.; Campbell, J.; Meldrum, F.; Christenson, H. Topographical control of crystal nucleation. Crystal Growth \& Design 2012, 12 (2), 750-755.

79. Lee, M. H.; Yoon, K. J.; Ko, S. W. Synthesis of a vinyl monomer containing $\beta$ cyclodextrin and grafting onto cotton fiber. Journal of Applied Polymer Science 2001, 80 (3), 438-446.

80. Lin, C.; Du, Y. Effect of surface topographies of PTFE and polyimide as characterized by atomic force microscopy on the heterogeneous nucleation of isotactic polypropylene. Materials chemistry and physics 1999, 58 (3), 268-275.

81. Zhang, Y.; Wang, M.; Lin, X.; Huang, W. Effect of substrate surface microstructure on heterogeneous nucleation behavior. Journal of Materials Science \& Technology 2012, 28 (1), 67-72.

82. Price, F., Nucleation; AC Zettlemoyer. New York: Marcel Dekker: 1969.

83. Turnbull, D. Kinetics of heterogeneous nucleation. The Journal of Chemical Physics 1950, 18 (2), 198-203.

84. Boinovich, L.; Emelyanenko, A. M.; Korolev, V. V.; Pashinin, A. S. Effect of wettability on sessile drop freezing: when superhydrophobicity stimulates an extreme freezing delay. Langmuir 2014, 30 (6), 1659-1668. 
85. Tang, Y.-r.; Li, T.; Ye, H.-m.; Xu, J.; Guo, B.-h. The effect of polymer-substrate interaction on the nucleation property: Comparing study of graphene and hexagonal boron nitride Nanosheets. Chinese Journal of Polymer Science 2016, 34 (8), 1021-1031.

"for Table of Contents use only"

\section{Nucleation of poly(lactide) on the surface of different fibers}

Bao Wang ${ }^{\mathrm{a}}$, Tao Wen ${ }^{\mathrm{b}}$, Xiuqin Zhang ${ }^{\mathrm{c}}$, Agnieszka Tercjak ${ }^{\mathrm{d}}$, Xia Dong ${ }^{\mathrm{b}}$, Alejandro J. Müller $^{\mathrm{e}, \mathrm{f}}$, Dujin Wang ${ }^{\mathrm{b}, *}$, Dario Cavallo ${ }^{\mathrm{a}, *}$ 


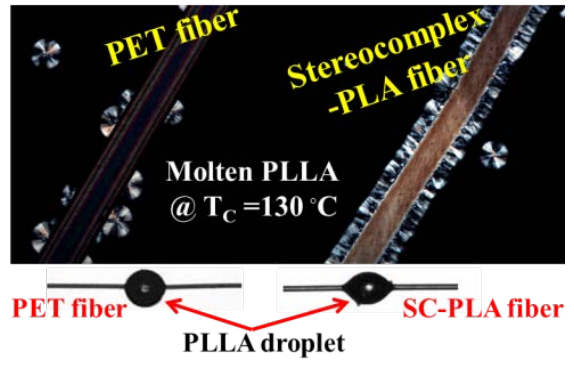

